\title{
Nickel-Catalyzed Decarbonylative Alkynylation of Acyl Fluorides with Terminal Alkynes under Copper-Free Conditions
}

\author{
Qiang Chen ${ }^{\mathrm{a}}$ \\ Liyan Fua \\ Jingwen You ${ }^{a}$ \\ Yasushi Nishihara*b (iD) \\ a Graduate School of Natural Science and Technology, Okayama \\ University, 3-1-1 Tsushimanaka, Kita-ku, Okayama 700-8530, Japan \\ ${ }^{b}$ Research Institute for Interdisciplinary Science, Okayama University, \\ 3-1-1 Tsushimanaka, Kita-ku, Okayama 700-8530, Japan \\ ynishiha@okayama-u.ac.jp \\ Published as part of the Cluster Modern Nickel-Catalyzed Reactions
}
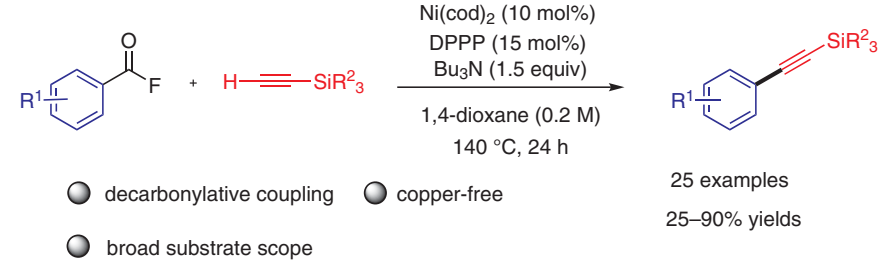

Received: 09.09.2020

Accepted after revision: 21.09.2020

Published online: 28.10 .2020

DOI: 10.1055/s-0040-1705954; Art ID: st-2020-k0490-c

Abstract Nickel-catalyzed decarbonylative alkynylation of acyl fluorides with terminal silylethynes under copper-free conditions is described. This newly developed method has a wide substrate scope, affording internal silylethynes in moderate to high yields. The formation of 1,3-diynes as homocoupled products and conjugate enones as carbonyl-retentive products were effectively suppressed.

Key words nickel catalysis, decarbonylation, silylalkynes, alkynylation, acyl fluorides, sila-Sonogashira-Hagihara reaction

Over the past few decades, the Sonogashira-Hagihara (S-H) reaction, ${ }^{1}$ the $\mathrm{Pd} / \mathrm{Cu}$-co-catalyzed coupling of terminal alkynes with aryl (pseudo)halides, has resulted in significant progress in the construction of $\mathrm{C}\left(\mathrm{sp}^{2}\right)-\mathrm{C}(\mathrm{sp})$ bonds. ${ }^{2}$ Further explorations of this reaction have involved optimizing the reaction conditions to avoid the formation of homocoupled byproducts through the use of copper-free reactions ${ }^{3}$ or sila-S-H reactions, 4,5 and the development of more economical catalyst systems to replace expensive Pd with $\mathrm{Ni} / \mathrm{Cu},{ }^{6} \mathrm{Ni},{ }^{7}$ or $\mathrm{Cu}^{8}{ }^{8}$ However, in most cases, palladium is still used as the primary catalyst for the $\mathrm{S}-\mathrm{H}$ reaction, and only a few examples have been reported in which nickel or other metals have been used as catalysts.

Finding a naturally abundant coupling partner is another approach to optimizing the $\mathrm{S}-\mathrm{H}$ reaction. Sodium sulfonates, ${ }^{9}$ arylhydrazines, ${ }^{10}$ and arylsulfonyl hydrazides ${ }^{11}$ have been employed as coupling partners instead of the commonly used aryl or vinyl (pseudo)halides, but there is still a need to develop other coupling partners that can be obtained from naturally abundant starting materials. Recently, esters and amides derived from carboxylic acids have been applied as coupling partners in $\mathrm{S}-\mathrm{H}$ reactions (Scheme 1a). ${ }^{12-14}$ The group of Itami and Yamaguchi developed the first example of a Pd/Cu-co-catalyzed alkynylation of aromatic esters in a decarbonylative manner. ${ }^{12}$ Meanwhile, Rueping and co-workers developed an effective $\mathrm{Ni} / \mathrm{Cu}$ cocatalyst for the deamidative cross-coupling of silylated terminal alkynes with amides under base-free conditions, which permitted the direct conversion of amides into alkynes. ${ }^{13}$ An example in which copper is not used as a cocatalyst is the Pd-catalyzed decarbonylative alkynylation of amides with terminal alkynes, a reaction that can be applied to various alkynes bearing aryl, alkyl, or silyl substituents. ${ }^{14}$

Acyl fluorides, which can be prepared from the corresponding carboxylic acids, have been widely used in carbon-carbon and carbon-heteroatom bond-formation reactions ${ }^{15}$ as 'RCO' (carbonyl-retentive) ${ }^{16}$ or ' $\mathrm{R}$ ' (decarbonylative $)^{17-21}$ sources, due to their unique stability and reactivity. In the decarbonylation reaction, since the first examples of decarbonylative transformations of acid fluorides were disclosed, ${ }^{17}$ acyl fluorides have been used as coupling partners in reduction, ${ }^{18}$ Suzuki-Miyaura-type arylation, ${ }^{19}$ and direct $\mathrm{C}-\mathrm{H}$ arylation reactions. ${ }^{20}$ As an extension of our research on various decarbonylative reactions of acyl fluorides, ${ }^{21}$ we recently succeeded in developing a $\mathrm{Pd} / \mathrm{Cu}$-co-catalyzed decarbonylative sila-S-H alkynylation of acyl fluorides with silylated internal alkynes (Scheme 1b). ${ }^{22}$ The reaction proceeds through cleavage of the C-Si other hand, because silylated terminal alkynes can be subjected to further conversions, more-direct methods for reacting silylated terminal alkynes with acyl fluorides, especially by using cheaper catalyst systems, are still highly desirable. Here, we report a nickel-catalyzed decarbonylative alkynylation of acyl fluorides with silylated alkynes under copper-free condition, which provides a direct method for converting acyl fluorides into the corresponding internal silylalkynes (Scheme 1c). bond, so that no silicon is present in the product. On the 


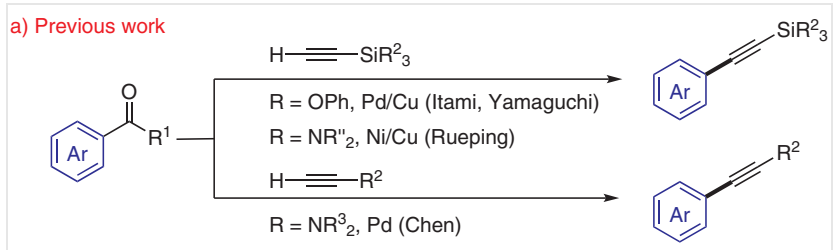

b) Our previous work

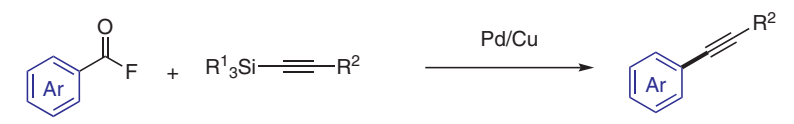

c) This work

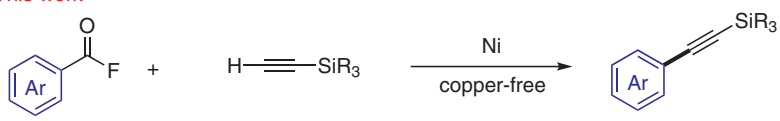

Scheme 1 Decarbonylative alkynylation reactions of carboxylic acid derivatives

To optimize the reaction conditions, we initially conducted the reaction by employing 2-naphthoyl fluoride (1a) and ethynyl(triisopropyl)silane (2a) as coupling partners and $\mathrm{Ni}(\operatorname{cod})_{2}$ as the catalyst in 1,4-dioxane (Table 1$)$. The nature of the phosphine ligands had a significant effect on the outcome of the reaction (Table 1, entries 1-3). When 1,3bis(diphenylphosphino)propane (DPPP) was used as a ligand, the desired product was obtained in $64 \%$ GC yield, twice that given by 1,2-bis(diphenylphosphino)ethane (DPPE). Other bidentate or monodentate phosphine ligands gave much lower yields [see Supporting Information (SI), Table S2]. Subsequently, toluene, DMF, and DMI were tested as solvents instead of 1,4-dioxane, but all of these gave poor yields of 3aa (entries 4 and 5 and SI, Table S3). To our delight, reducing the amount of $\mathbf{2 a}$ to two equivalents afforded 3aa in $68 \%$ yield (entry 6). However, when the amount of 2a was further reduced to one equivalent, only $42 \%$ of 3aa was obtained (SI, Table S4). Furthermore, lowering the amount of DPPP to $15 \mathrm{~mol} \%$ gave 3aa in $65 \%$ yield (entry 7 ). After screening a series of inorganic and organic bases, we found that when $\mathrm{Bu}_{3} \mathrm{~N}$ was employed instead of $\mathrm{Et}_{3} \mathrm{~N}$, the yield of 3aa was improved to $73 \%$ (entry 8 ). Compound 1a was converted to 3aa in 58\% yield in the absence of the base (entry 9). Interestingly, the addition of CuI, which is generally required for $\mathrm{S}-\mathrm{H}$ reactions, dramatically reduced the yield of the target product (entry 10). The activity of 2naphthoyl chloride was lower than that of 2-naphthoyl fluoride, yielding only $33 \%$ of 3aa (entry 11 ), implying that the acyl fluoride has unique properties in the decarbonylative alkynylation reaction. This reaction did not proceed at all in the absence of the Ni catalyst (entry 12).
Table 1 Optimization of the Reaction Conditions ${ }^{\mathrm{a}}$

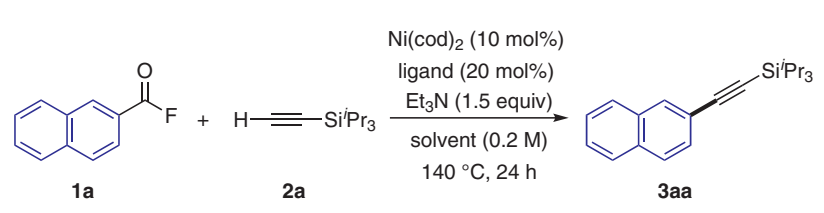

\begin{tabular}{cllc}
\hline Entry & Ligand (20 mol\%) & Solvent & Yield $^{\mathrm{b}}(\%)$ \\
\hline 1 & DPPE & 1,4-dioxane & 32 \\
2 & DPPP & 1,4-dioxane & 64 \\
3 & DCYPE & 1,4-dioxane & 5 \\
4 & DPPP & toluene & 51 \\
5 & DPPP & DMF & 18 \\
$6^{c}$ & DPPP & 1,4-dioxane & 68 \\
$7^{c, d}$ & DPPP & 1,4-dioxane & 65 \\
$8^{c, d, e ~}$ & DPPP & 1,4-dioxane & 73 \\
$9^{c, f}$ & DPPP & 1,4-dioxane & 58 \\
$10^{c, 9}$ & DPPP & 1,4-dioxane & 13 \\
$11^{c, h}$ & DPPP & 1,4-dioxane & 33 \\
$12^{c, i}$ & DPPP & 1,4-dioxane & 0 \\
\hline
\end{tabular}

a Reaction conditions: $1 \mathrm{a}(0.2 \mathrm{mmol}), \mathbf{2 a}(0.6 \mathrm{mmol}), \mathrm{Ni}(\operatorname{cod})_{2}(0.02$ $\mathrm{mmol})$, ligand $(0.04 \mathrm{mmol}), \mathrm{Et}_{3} \mathrm{~N}\left(1.5\right.$ equiv), solvent $(1 \mathrm{~mL}), 140{ }^{\circ} \mathrm{C}, 24 \mathrm{~h}$.

${ }^{\mathrm{b}} \mathrm{GC}$ yields with dodecane as an internal standard.

c $2 \mathbf{a}(2.0$ equiv).

d DPPP (15 mol\%).

${ }^{e} \mathrm{Bu}_{3} \mathrm{~N}$ instead of $\mathrm{Et}_{3} \mathrm{~N}$.

${ }^{\mathrm{f}}$ No base.

9 With Cul (10 mol \%).

h 2-Naphthoyl chloride instead of $\mathbf{1 a}$.

Without $\mathrm{Ni}(\operatorname{cod})_{2}$.

With the optimized reaction conditions in hand [ $\mathrm{Ni}(\operatorname{cod})_{2}(10 \mathrm{~mol} \%), \operatorname{DPPP}(15 \mathrm{~mol} \%), \mathrm{Bu}_{3} \mathrm{~N}$ (1.5 equiv), 140 ${ }^{\circ} \mathrm{C}$, we investigated the substrate scope of acyl fluorides (Scheme 2). Naphthoyl fluorides $\mathbf{1 a}$ and $\mathbf{1 b}$ and benzoyl fluoride (1c) were smoothly converted into the corresponding products 3aa-ca in good yields. Acyl fluorides with electron-donating methyl (1d), tert-butyl (1e), or phenyl (1f) groups in the para-position were efficiently converted into the corresponding alkynylsilanes 3da-fa in yields of 7690\%. Although it is known that carbon-OMe bonds are cleaved in the presence of nickel catalysts, ${ }^{23}$ substrate $\mathbf{~} \mathbf{g}$ bearing a methoxy group nevertheless gave 3ga in $81 \%$ yield. Substrate $\mathbf{1 h}$ bearing an acetal functional group was also tolerated in this reaction, giving product 3ha in $90 \%$ yield. Alkynylsilanes 3ia-ma bearing electron-withdrawing groups in the para-position were also obtained in moderate to good yields. Unlike the previously reported coupling of aryl esters, ${ }^{12}$ this reaction tolerates both methyl and phenyl esters. Moreover, acyl fluoride $\mathbf{1 n}$ functionalized with a fluoro group was also tolerated. ${ }^{24} \mathrm{Next}$, the steric effects of ortho-substituents on the acyl fluoride were evaluated. Acyl fluoride 10 with an ortho-Me group reacted smoothly, yielding 3oa in $81 \%$ yield. However, when the Me group was replaced by a bulkier Ph group, the yield of 3pa decreased 
to $58 \%$, and only $53 \%$ of product $3 q$ a was obtained from 2,4,6-trimethylbenzoyl fluoride (1q), which has a higher steric hindrance. Heterocyclic acyl fluorides 1r-t were also suitable substrates, giving products 3ra-ta in moderate yields. The reaction of $\mathbf{1} \mathbf{u}$, derived from commercially available probenecid, afforded 3ua in $78 \%$ yield. We also synthesized the conjugated enyne 3va in $76 \%$ yield as a 1:1 mixture of $(E)$ - and $(Z)$-isomers.
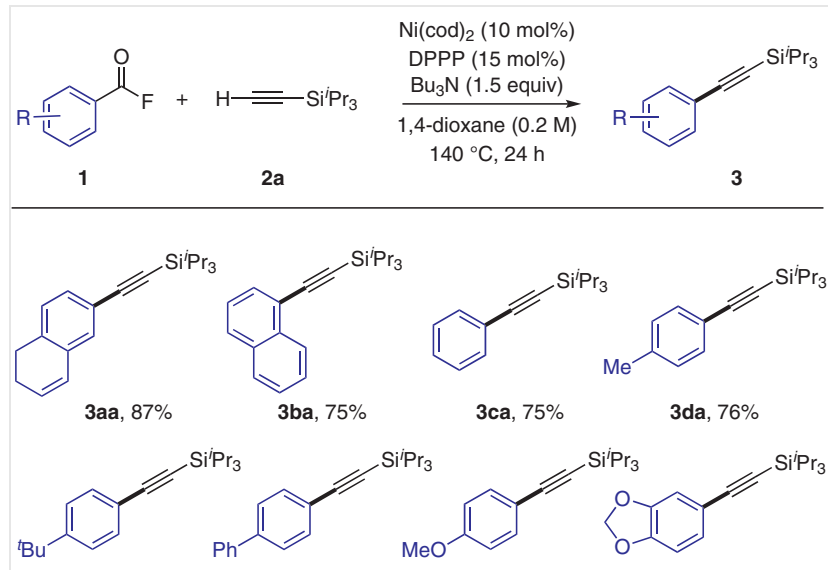

3ca, $75 \%$

3da, $76 \%$

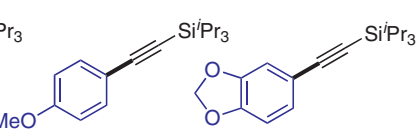

3ea, $90 \%$

3ga, $81 \%$

3ha, $90 \%$

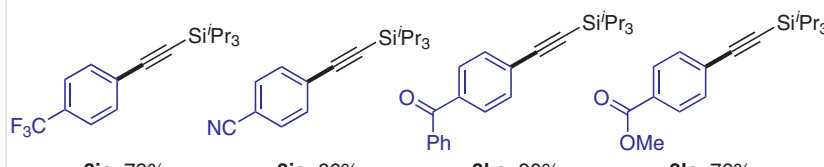

3ia, $79 \%$

3ja, $66 \%$

3ka, $90 \%$

3la, $76 \%$

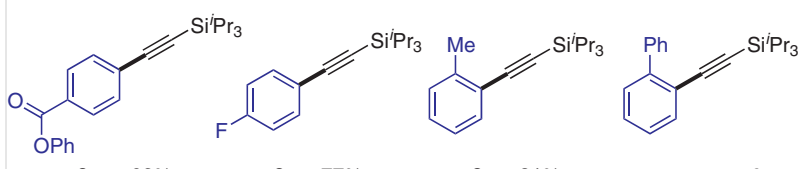

3ma, $62 \%$

3na, $77 \%$

3pa, $58 \%$

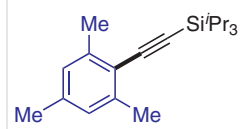

$3 q a, 53 \%$ a

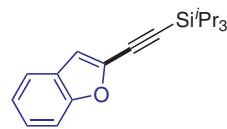

3ra, $52 \%$

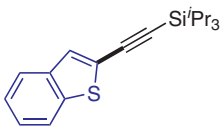

3sa, $44 \%$

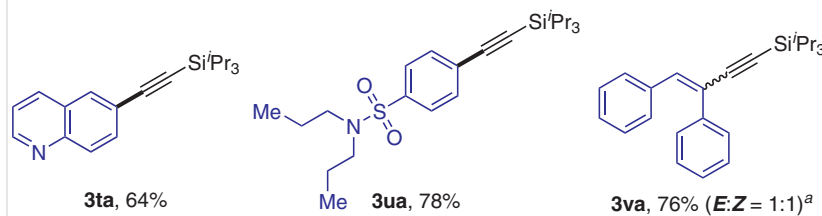

Scheme 2 Scope of acyl fluorides: Reagents and conditions: 1 (0.2 $\mathrm{mmol}), 2 \mathrm{a}(0.4 \mathrm{mmol}), \mathrm{Ni}(\mathrm{cod})_{2}(0.02 \mathrm{mmol}), \mathrm{DPPP}(0.03 \mathrm{mmol}), \mathrm{Bu}_{3} \mathrm{~N}$ (0.3 mmol), 1,4-dioxane $(1 \mathrm{~mL}), 140{ }^{\circ} \mathrm{C}, 24 \mathrm{~h}$. Yields of the pure isolated products 3 are reported. ${ }^{a} 1(0.3 \mathrm{mmol}), 2 \mathrm{a}(0.2 \mathrm{mmol}), 48 \mathrm{~h}$.

Next, the effect of the silyl group on the alkyne $\mathbf{2}$ was investigated (Scheme 3). Regardless of whether steric hindrance by the silyl group was increased or reduced, the yield of the desired product decreased, with 3ab, 3ac, and 3ad being obtained in yields of 25,44 , and $49 \%$, respectively. To our delight, however, when we increased the amount of $\mathbf{2}$ to five equivalents, 3ac and 3ad were obtained in yields of 66 and 62\%, respectively. Attempts were also made to extend the range of substrate to include terminal alkynes with aryl or alkyl groups. However, when ethynylbenzene or oct1-yne was used as a coupling partner, the desired product was not obtained (see SI for details), probably due to trimerization or polymerization of the aromatic or aliphatic terminal alkyne by the Ni catalyst.

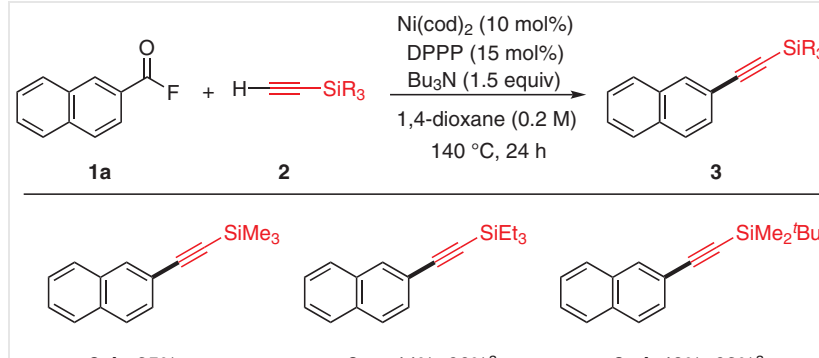

3ab, $25 \%$

3ac, $44 \%, 66 \%^{\text {a }}$

3ad, $49 \%, 62 \%^{a}$

Scheme 3 Scope of silylated alkynes. Reagents and conditions: 1 a $(0.2$ $\mathrm{mmol}), 2$ (0.4 mmol), Ni(cod) 2 (0.02 mmol), DPPP (0.03 mmol), Bu $\mathrm{Bu}_{3}$ $(0.3 \mathrm{mmol}), 1,4$-dioxane $(1 \mathrm{~mL}), 140{ }^{\circ} \mathrm{C}, 24 \mathrm{~h}$. Yields of the pure isolated products $\mathbf{3}$ are reported. ${ }^{\text {a }} \mathbf{2}(5$ equiv).

By combining the reaction mechanism proposed in previous reports ${ }^{2,25}$ with our experimental results described above, we developed a plausible catalytic cycle for this reaction, shown in Scheme 4. First, oxidative addition of the acyl fluoride to $\mathrm{Ni}(0)$ proceeds through $\mathrm{C}-\mathrm{F}$ bond cleavage to give complex $\mathbf{A}$. This reacts with silyl alkyne $\mathbf{2}$ under basic conditions to give complex $\mathbf{B}$, as proposed for a reported copper-free palladium-catalyzed $\mathrm{S}-\mathrm{H}$ reaction. ${ }^{26}$ Subsequent decarbonylation gives intermediate $\mathbf{C}$, and further $\mathrm{CO}$ extrusion gives intermediate $\mathbf{D}$, from which reductive elimination yields the cross-coupled product 3 with regeneration of the initial $\mathrm{Ni}(0)$ catalyst. Because few aryl alkynyl ketones were generally produced, $\mathrm{CO}$ extrusion might occur before reductive elimination and might constitute a ratelimiting step. Considering the formation of enyne $\mathbf{4}$ as a byproduct, oxidative addition of silylated alkynes 2 to $\mathrm{Ni}(0)$ results in the formation of complex $\mathbf{E}$, which further reacts with a second molecule of $\mathbf{2}$ to give $\mathbf{4}$ through homohydroalkynylation. ${ }^{27}$ Another possibility for the formation of intermediate $\mathbf{B}$ without copper salt assistance is as follows. As shown in Table 1, entry 9, the fact that the coupled products 3 can be obtained in the absence of a base suggests that this reaction may proceed by ligand exchange between complex $\mathbf{A}$ and complex $\mathbf{E}$, resulting in the formation of complex B along with the hydrido(fluoro)nickel complex. Thus, the yield of the desired product 3 might be affected by a competing oxidative addition of acyl fluoride $\mathbf{1}$ or silylated alkyne 2 to the $\mathrm{Ni}(0)$ catalyst. 


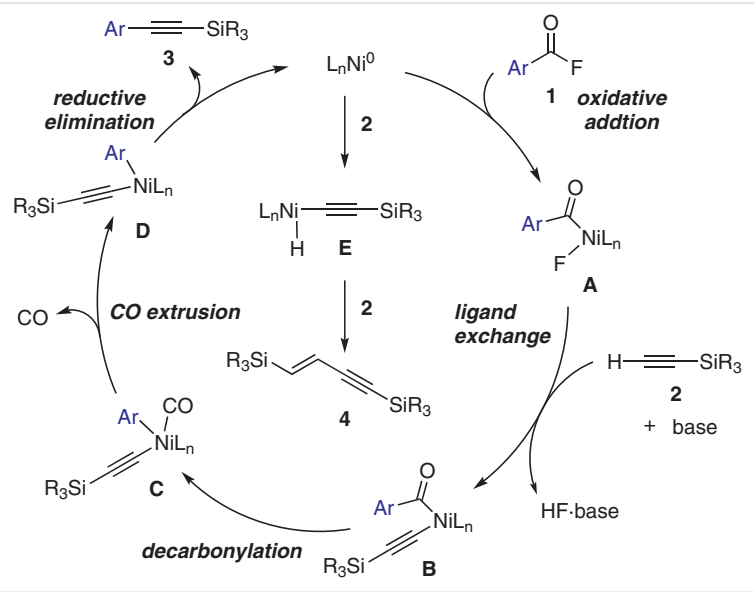

Scheme 4 Proposed mechanism

In summary, we have developed a nickel-catalyzed, copper-free $\mathrm{S}-\mathrm{H}$ reaction that proceeds by a decarbonylative pathway with acyl fluorides as coupling partners and shows a broad substrate scope. ${ }^{28}$ Detailed density functional theory calculations are currently being performed to elucidate the sequence of transmetalation and decarbonylation in the catalytic cycle.

\section{Acknowledgment}

We thank Ms. Megumi Kosaka and Mr. Motonari Kobayashi (Department of Instrumental Analysis, Advanced Science Research Center, Okayama University) for performing elemental analyses and the SCNMR Laboratory (Okayama University) for the NMR spectral measurements.

\section{Supporting Information}

Supporting information for this article is available online at https://doi.org/10.1055/s-0040-1705954.

\section{References and Notes}

(1) (a) Sonogashira, K.; Tohda, Y.; Hagihara, N. Tetrahedron Lett. 1975, 4467. (b) Cassar, L. J. Organomet. Chem. 1975, 93, 253. (c) Dieck, H. A.; Heck, F. R. J. Organomet. Chem. 1975, 93, 259.

(2) For selected examples, see: (a) Sonogashira, K. In Comprehensive Organic Synthesis Vol. 3; Trost, B. M.; Fleming, I., Ed.; Pergamon: Oxford, 1991, Chap. 2.4, 521. (b) Sonogashira, K. J. Organomet. Chem. 2002, 653, 46. (c) Negishi, E.; Anastasia, L. Chem. Rev. 2003, 103, 1979. (d) Nicolaou, K. C.; Bulger, P. G.; Sarlah, D. Angew. Chem. Int. Ed. 2005, 44, 4442. (e) Yin, L.; Liebscher, J. Chem. Rev. 2007, 107, 133. (f) Chinchilla, R.; Nájera, C. Chem. Rev. 2007, 107, 874. (g) Thomas, A. M.; Sujatha, A.; Anilkumar, G. RSC Adv. 2014, 4, 21688. (h) Karak, M.; Barbosa, L. C. A.; Hargaden, G. C. RSC Adv. 2014, 4, 53442.

(3) For selected examples, see: (a) Leadbeater, N. E.; Tominack, B. J. Tetrahedron Lett. 2003, 44, 8653. (b) Soheili, A.; AlbanezeWalker, J.; Murry, J. A.; Dormer, P. G.; Hughes, D. L. Org. Lett.
2003, 5, 4191. (c) Ljungdahl, T.; Pettersson, K.; Albinsson, B.; Mårtensson, J. J. Org. Chem. 2006, 71, 1677. (d) Jiang, Q.; Li, H.; Zhang, X.; Xu, B.; Su, W. Org. Lett. 2018, 20, 2424. (e) He, J.; Yang, K.; Zhao, J.; Cao, S. Org. Lett. 2019, 21, 9714.

(4) (a) Nishihara, Y.; Ikegashira, K.; Mori, A.; Hiyama, T. Chem. Lett. 1997, 1233. (b) Nishihara, Y.; Ikegashira, K.; Hirabayashi, K.; Ando, J.-i. J. Org. Chem. 2000, 65, 1780. (c) Nishihara, Y.; Inoue, E.; Okada, Y.; Takagi, K. Synlett 2008, 3041. (d) Nishihara, Y.; Inoue, E.; Ogawa, D.; Okada, Y.; Noyori, S.; Takagi, K. Tetrahedron Lett. 2009, 50, 4643. (e) Nishihara, Y.; Noyori, S.; Okamoto, T.; Suetsugu, M.; Iwasaki, M. Chem. Lett. 2011, 40, 972. (f) Nishihara, Y.; Inoue, E.; Noyori, S.; Ogawa, D.; Okada, Y.; Iwasaki, M.; Takagi, K. Tetrahedron 2012, 68, 4869. (g) Nishihara, Y.; Ogawa, D.; Noyori, S.; Iwasaki, M. Chem. Lett. 2012, 41, 1053.

(5) (a) Koseki, Y.; Omino, K.; Anzai, S.; Nagasaka, T. Tetrahedron Lett. 2000, 41, 2377. (b) Halbes, U.; Pale, P. Tetrahedron Lett. 2002, 43 , 2039. (c) Sørensen, U. S.; Pombo-Villar, E. Tetrahedron 2005, 61, 2697. (d) Zhou, Z.-L.; Zhao, L.; Zhang, S.; Vincent, K.; Lam, S.; Henze, D. Synth. Commun. 2012, 42, 1622. (e) Capani, J. S. Jr.; Cochran, J. E.; Liang, J. J. Org. Chem. 2019, 84, 9378.

(6) For selected examples, see: (a) Beletskaya, I. P.; Latyshev, G. V.; Tsvetkov, A. V.; Lukashev, N. V. Tetrahedron Lett. 2003, 44, 5011. (b) Wang, L.; Li, P.; Zhang, Y. Chem. Commun. 2004, 514. (c) Vechorkin, O.; Barmaz, D.; Proust, V.; Hu, X. J. Am. Chem. Soc. 2009, 131, 12078. (d) Pérez García, P. M.; Ren, P.; Scopelliti, R.; Hu, X. L. ACS Catal. 2015, 5, 1164.

(7) For selected examples, see: (a) Biradar, D. B.; Gau, H.-M. Chem. Commun. 2011, 47, 10467. (b) Xu, G.; Li, X.; Sun, H. J. Organomet. Chem. 2011, 696, 3011. (c) Moghaddam, F. M.; Tavakoli, G.; Rezvani, H. R. Catal. Commun. 2015, 60, 82. (d) Nowrouzi, N.; Zarei, M. Tetrahedron 2015, 71, 7847.

(8) For selected examples, see: (a) Okuro, K.; Furuune, M.; Enna, M.; Miura, M.; Nomura, M. J. Org. Chem. 1993, 58, 4716. (b) Gujadhur, R. K.; Bates, C. G.; Venkataraman, D. Org. Lett. 2001, 3, 4315. (c) Ma, D.; Liu, F. Chem. Commun. 2004, 1934. (d) Saejueng, P.; Bates, C. G.; Venkataraman, D. Synthesis 2005, 1706. (e) Tsai, W.-T.; Lin, Y.-Y.; Chen, Y.-A.; Lee, C.-F. Synlett 2014, 25, 443. (f) Zhang, H.; Sun, N.; Hu, B.; Shen, Z.; Hu, X.; Jin, L. Org. Chem. Front. 2019, 6, 1983.

(9) Xu, Y.; Zhao, J.; Tang, X.; Wu, W.; Jiang, H. Adv. Synth. Catal. 2014, 356, 2029.

(10) Zhao, Y.; Song, Q. Chem. Commun. 2015, 51, 13272.

(11) (a) Qian, L.-W.; Sun, M.; Dong, J.; Xu, Q.; Zhou, Y.; Yin, S.-F. J. Org. Chem. 2017, 82, 6764. (b) Tian, Z.-Y.; Wang, S.-M.; Jia, S.-J.; Song, H.-X.; Zhang, C.-P. Org. Lett. 2017, 19, 5454.

(12) Okita, T.; Kumazawa, K.; Takise, R.; Muto, K.; Itami, K.; Yamaguchi, J. Chem. Lett. 2017, 46, 218.

(13) Srimontree, W.; Chatupheeraphat, A.; Liao, H.-H.; Rueping, M. Org. Lett. 2017, 19, 3091.

(14) Liu, L.; Zhou, D.; Liu, M.; Zhou, Y.; Chen, T. Org. Lett. 2018, 20 , 2741.

(15) For selected reviews on transition-metal-catalyzed transformations of acyl fluorides, see: (a) Blanchard, N.; Bizet, V. Angew. Chem. Int. Ed. 2019, 58, 6814. (b) Zhao, Q.; Szostak, M. ChemSusChem 2019, 12, 2983. (c) Ogiwara, Y.; Sakai, N. Angew. Chem. Int. Ed. 2020, 59, 574. (d) Wang, Z.; Wang, X.; Nishihara, Y. Chem. Asian J. 2020, 15, 1234.

(16) (a) Zhang, Y.; Rovis, T. J. Am. Chem. Soc. 2004, 126, 15964. (b) Ogiwara, Y.; Maegawa, Y.; Sakino, D.; Sakai, N. Chem. Lett. 2016, 45, 790. (c) Ogiwara, Y.; Sakino, D.; Sakurai, Y.; Sakai, N. Eur. J. Org. Chem. 2017, 4324. (d) Boreux, A.; Indukuri, K.; Gagosz, F.; Riant, O. ACS Catal. 2017, 7, 8200. (e) Ogiwara, Y.; Iino, Y.; Sakai, N. Chem. Eur. J. 2019, 25, 6513. (f) Pan, F.-F.; Guo, 
P.; Li, C.-L.; Su, P.; Shu, X.-Z. Org. Lett. 2019, 21, 3701. (g) Han, J.; Zhou, W.; Zhang, P.-C.; Wang, H.; Zhang, R.; Wu, H.-H.; Zhang, J. ACS Catal. 2019, 9, 6890. (h) Ogiwara, Y.; Hosaka, S.; Sakai, N. Organometallics 2020, 39, 856. (i) Sakurai, Y.; Ogiwara, Y.; Sakai, N. Chem. Eur. J. 2020, 26, 12972.

(17) Keaveney, S. T.; Schoenebeck, F. Angew. Chem. Int. Ed. 2018, 57, 4073.

(18) Ogiwara, Y.; Sakurai, Y.; Hattori, H.; Sakai, N. Org. Lett. 2018, 20 , 4204.

(19) Malapit, C. A.; Bour, J. R.; Brigham, C. E.; Sanford, M. S. Nature 2018, 563, 100.

(20) Sakurai, S.; Yoshida, T.; Tobisu, M. Chem. Lett. 2019, 48, 94.

(21) (a) Okuda, Y.; Xu, J.; Ishida, T.; Wang, C.-a.; Nishihara, Y. ACS Omega 2018, 3, 13129. (b) Wang, Z.; Wang, X.; Nishihara, Y. Chem. Commun. 2018, 54, 13969. (c) Wang, X.; Wang, Z.; Liu, L.; Asanuma, Y.; Nishihara, Y. Molecules 2019, 24, 1671. (d) Wang, X.; Wang, Z.; Nishihara, Y. Chem. Commun. 2019, 55, 10507. (e) Fu, L.; Chen, Q.; Wang, Z.; Nishihara, Y. Org. Lett. 2020, 22, 2350.

(22) Chen, Q.; Fu, L.; Nishihara, Y. Chem. Commun. 2020, 56, 7977.

(23) For selected examples, see: (a) Cornella, J.; Zarate, C.; Martin, R. Chem. Soc. Rev. 2014, 43, 8081. (b) Tobisu, M.; Chatani, N. Acc. Chem. Res. 2015, 48, 1717. (c) Zeng, H.; Qiu, Z.; DomínguezHuerta, A.; Hearne, Z.; Chen, Z.; Li, C.-J. ACS Catal. 2017, 7, 510.

(24) 4-Chlorobenzoyl fluoride gave the desired product in only $34 \%$ yield.
(25) Gazvoda, M.; Virant, M.; Pinter, B.; Košmrlj, J. Nat. Commun. 2018, 9, 4814

(26) Tougerti, A.; Negri, S.; Jutand, A. Chem. Eur. J. 2007, 13, 666.

(27) A Ni-catalyzed homohydroalkynylation of silylated alkynes has been reported; see: Shirakura, M.; Suginome, M. J. Am. Chem. Soc. 2008, 130, 5410.

(28) Silylated Internal Alkynes 3: General Procedure An oven-dried $20 \mathrm{~mL}$ Schlenk tube containing a magnetic stirring bar was charged with $\mathrm{Ni}(\operatorname{cod})_{2}(5.5 \mathrm{mg}, 0.02 \mathrm{mmol}, 10$ mol\%), DPPP (12.4 mg, $0.03 \mathrm{mmol}, 15 \mathrm{~mol} \%$ ), 1,4-dioxane (1 mL) under dry $\mathrm{N}_{2}$, and the mixture was stirred for $30 \mathrm{~s}$ at r.t. The appropriate acyl fluoride $1(0.2 \mathrm{mmol})$, silyl alkyne 2 (0.4 $\mathrm{mmol})$, and $\mathrm{Bu}_{3} \mathrm{~N}(0.3 \mathrm{mmol})$ were added, and the mixture was heated at $140{ }^{\circ} \mathrm{C}$ in a heating block with stirring for $24 \mathrm{~h}$, then cooled to r.t. The reaction was quenched with sat. aq $\mathrm{NH}_{4} \mathrm{Cl}$, and the mixture was extracted with $\mathrm{Et}_{2} \mathrm{O}$. The combined organic phase was dried $\left(\mathrm{MgSO}_{4}\right)$ and concentrated under vacuum, and the residue was purified by column chromatography (silica gel, EtOAc-hexane).

Triisopropyl(2-naphthylethynyl)silane (3aa) $)^{13}$

Yellow oil; yield: $53.6 \mathrm{mg}(87 \%) ; R_{f}=0.54$ (hexane). ${ }^{1} \mathrm{H}$ NMR $\left(400 \mathrm{MHz}, \mathrm{CDCl}_{3}\right): \delta=1.19(\mathrm{~s}, 21 \mathrm{H}), 7.48-7.50(\mathrm{~m}, 2 \mathrm{H}), 7.54$ (dd, $J=8.4,2.0 \mathrm{~Hz}, 1 \mathrm{H}), 7.76-7.82(\mathrm{~m}, 3 \mathrm{H}), 8.02(\mathrm{~s}, 1 \mathrm{H}) .{ }^{13} \mathrm{C}\left\{{ }^{1} \mathrm{H}\right\}$ NMR $\left(101 \mathrm{MHz}, \mathrm{CDCl}_{3}\right): \delta=11.5,18.9,91.1,107.6,121.0,126.6$, $126.8,127.85,127.87,128.0,129.0,132.0,133.0,133.1$. 